\title{
Quality of Life of Older Persons in Rural Bangladesh
}

\author{
Mohammad Abbas Uddin \\ Nursing Service, Sadar Hospital, Lakshmipur, Bangladesh
}

Email address:

uabbas9@gmail.com

\section{To cite this article:}

Mohammad Abbas Uddin. Quality of Life of Older Persons in Rural Bangladesh. American Journal of Applied Psychology. Vol. 6, No. 5, 2017, pp. 106-109. doi: 10.11648/j.ajap.20170605.14

Received: July 11, 2017; Accepted: July 26, 2017; Published: October 19, 2017

\begin{abstract}
The proportion of older persons in Bangladesh is significantly increasing due to demographic transition. This will bring new demands related to older persons' health and social needs. Expeditious development of initiatives to face these coming challenges is required. The aim of this study was to assess older persons' quality of life in southern Bangladesh, and the relationship between quality of life and various socio-demographic characteristics in this region. Data were collected from 280 older persons from 10 villages. The Bengali version of WHOQOL-BREF questionnaire was used to measure the quality of life. Descriptive statistics were used to analyze demographic and quality of life data. One way classification of analysis of variance (ANOVA) was used to compare two groups of older persons with different socio-demographic characteristics. The study found that older persons reported a moderate quality of life score $(\mathrm{M}=73.82, \mathrm{SD}=9.35)$. Results also showed that being male, married, literate, living in an extended family, and having a medium family income, significantly contributed to a higher quality of life score. There is a need to identify the psychological and social problems that affect older persons' quality of life in order to prepare strategies to improve their quality of life. The authors believe that this study's findings will contribute to this process.
\end{abstract}

Keywords: Bangladesh, Older Persons, Quality of Life

\section{Introduction}

Today, older persons (those aged 60 and above) are living longer than in previous times. This is an effect of improved medical science. In addition, heredity, standard of living, healthy diet habits, abstaining from smoking, and engaging in physical activity can affect the longevity of older persons [1]. Worldwide, the proportion of older persons was $11.7 \%$ in 2013 [2]. The World Health Organization has estimated that this will increase to $22 \%$ by 2050 [3]. In the future, most older persons will live in developing countries [1]. In Bangladesh, a developing country, the proportion of older persons was $6.9 \%$ in 2011 [4]. It is estimated that this will rise to $20 \%$ by 2051 [5]. The increasing proportion of older persons is an important issue in Bangladesh.

Older persons may suffer from various health and social problems [6 and 7]. Their social problems may include inadequate financial support from the government, insufficient health care, weakening family care systems [8], and decreasing social interactions. All of these problems may contribute to reduced quality of life and even disability.
Quality of life is "an individual's perception of their position in life in the context of the culture and value systems in which they live and in relation to their goals, expectations, standards and concerns" [9]. It is important to investigate the lives of older persons and the problems that they face. It is hoped that, armed with this knowledge, policy makers and medical professionals will be able to develop strategies to slow down the onset of disability and ensure a good quality of life for older persons [10].

The majority of Bangladeshis (including older persons) live in rural areas [11]. These areas are considered disadvantageous due to their lack of modern facilities for citizens. This lack may affect older persons' quality of life. A study of older persons in a northern district of Bangladesh [12] found that they reported a low mean quality of life score. This study also reported that participant sex, family type, and occupation influenced quality of life scores. However, these results may not be transferable to other regions of Bangladesh due to regional differences in older persons' physical status, level of education, and economic status. The present study, therefore, investigates older persons' quality of life and its relationship to various socio-demographic 
characteristics in two southern districts of Bangladesh.

\section{Data and Methods}

A descriptive and cross-sectional study was conducted in 10 villages of two southern districts of Bangladesh. Data were collected by interviewing 280 older persons between September 2015 and January 2016. A demographic data form was used, and the Bengali version of WHOQOL-BREF questionnaire was used to measure quality of life. This instrument consists of 26 items. There are two items regarding overall quality of life and general health, and 24 further items over four domains: physical health (7 items), psychological factors (6 items), social relationships (3 items), and environmental factors ( 8 items). Each item was assessed via a 5-point Likert scale, with scores for each item ranging from 1 to 5 . In this study, the reliability of the WHOQOLBREF questionnaire was determined by Cronbach's Alpha Coefficient, and the value found was .92 , which was considered satisfactory. The total potential score for the 26 items was between 26 and 130. Total scores were categorized as either low (26-60), moderate (61-95) or high (96-130). Domain scores were also categorized into three levels (low, moderate and high) using the formula: (highest score - lowest score) $\div 3$.

This secondary data was analyzed using a statistical program (SPSS 13.0). Descriptive statistics, including frequency, percentage, mean and standard deviation, were used to analyze the older persons' demographic and quality of life data. The comparison between the two groups was carried out using one way classification of analysis of variance (ANOVA).

\section{Results}

Table 1. Demographic characteristics of older persons $(n=280)$.

\begin{tabular}{lll}
\hline Characteristics & Categories & Frequency (\%) \\
\hline \multirow{2}{*}{ Age $(\mathrm{M}=65.81, \mathrm{SD}=4.37)$} & $60-70$ years & $239(85.4)$ \\
& $71-75$ years & $14.6)$ \\
Gender & Male & $141(50.4)$ \\
& Female & $139(49.6)$ \\
Marital status & Married & $224(80.0)$ \\
& Widow & $56(20.0)$ \\
Education level & Illiteracy & $154(55.0)$ \\
& Literate & $126(45.0)$ \\
Employment status & Employed & $232(82.9)$ \\
& Unemployed & $48(17.1)$ \\
Type of family & Nuclear & $149(53.2)$ \\
& Extended & $131(46.8)$ \\
Family monthly income $[1$ USD $=80$ Taka $]$ & $300-6,000$ Taka & $201(71.8)$ \\
\hline
\end{tabular}

The majority $(85.4 \%)$ of older persons were between 60 and 70 years old. $50.4 \%$ were male and $49.60 \%$ were female. The majority $(80.0 \%)$ were married, and $55.0 \%$ were illiterate. Most (82.9\%) were employed. $53.2 \%$ of the sample lived in a nuclear type of family, and most $(71.8 \%)$ reported their family's monthly income as between 300 and 6,000 Taka.

Table 2. Disease characteristics of older persons $(n=280)$.

\begin{tabular}{ll}
\hline Diseases & Frequency (\%) \\
\hline Gastrointestinal problem & $261(93.2)$ \\
Joint Pain & $155(55.4)$ \\
Back pain & $123(43.9)$ \\
Hypertension & $64(22.9)$ \\
Asthma & $61(21.8)$ \\
Diabetes mellitus & $41(17.5)$ \\
\hline
\end{tabular}

Most older persons suffered from gastrointestinal problems $(93.2 \%)$. This was followed in frequency by joint pain $(55.4 \%)$, back pain $(43.9 \%)$, hypertension $(22.9 \%)$, asthma (21.8\%), and diabetes mellitus (17.5\%).

Table 3. Quality of life of older persons $(n=280)$.

\begin{tabular}{llll}
\hline Variable & Mean & Standard deviation & Level \\
\hline Quality of life & 73.82 & 9.35 & Moderate \\
Physical domain & 19.44 & 3.78 & Moderate \\
Psychological domain & 17.05 & 2.96 & Moderate \\
Social domain & 9.88 & 1.53 & Moderate \\
Environmental domain & 21.32 & 2.97 & Moderate \\
\hline
\end{tabular}

The mean quality of life score was 73.82 , which represents a moderate level of quality of life. Participants also reported moderate levels for all domains of quality of life.

Table 4. Distribution of subjects and quality of life scores with various socio-demographic characteristics $(n=280)$.

\begin{tabular}{|c|c|c|c|c|c|c|c|c|}
\hline \multirow{2}{*}{ Characteristics } & \multirow{2}{*}{ Categories } & \multicolumn{2}{|c|}{ Quality of Life score } & \multirow{2}{*}{$\begin{array}{l}\text { Sources of } \\
\text { variation }\end{array}$} & \multirow{2}{*}{$\begin{array}{l}\text { Degree of } \\
\text { freedom }\end{array}$} & \multirow{2}{*}{ Mean square } & \multirow{2}{*}{ F-value } & \multirow{2}{*}{ Sig } \\
\hline & & Mean & Standard Deviation & & & & & \\
\hline \multirow{2}{*}{ Age (years) } & $60-70$ & 74.17 & 9.20 & within & 1 & 209.043 & 2.405 & 122 \\
\hline & $71-75$ & 71.73 & 9.98 & between & 278 & 86.923 & & \\
\hline \multirow{2}{*}{ Gender } & Male & 75.76 & 9.07 & within & 1 & 1077.916 & 12.863 & 000 \\
\hline & Female & 71.84 & 9.23 & between & 278 & 83.799 & & \\
\hline Marital status & Married & 75.65 & 8.59 & within & 1 & 3766.889 & 50.818 & 000 \\
\hline
\end{tabular}




\begin{tabular}{|c|c|c|c|c|c|c|c|c|}
\hline \multirow{2}{*}{ Characteristics } & \multirow{2}{*}{ Categories } & \multicolumn{2}{|c|}{ Quality of Life score } & \multirow{2}{*}{$\begin{array}{l}\text { Sources of } \\
\text { variation }\end{array}$} & \multirow{2}{*}{$\begin{array}{l}\text { Degree of } \\
\text { freedom }\end{array}$} & \multirow{2}{*}{ Mean square } & \multirow{2}{*}{ F-value } & \multirow{2}{*}{ Sig } \\
\hline & & Mean & Standard Deviation & & & & & \\
\hline \multirow{3}{*}{ Education level } & Widowed & 66.48 & 8.65 & between & 278 & 74.125 & \multirow{3}{*}{18.538} & \multirow{3}{*}{000} \\
\hline & Illiterate & 71.70 & 9.46 & within & 1 & 1523.701 & & \\
\hline & Literate & 76.39 & 8.55 & between & 278 & 82.194 & & \\
\hline Employment & Employed & 73.99 & 9.48 & within & 1 & 42.789 & \multirow[t]{2}{*}{489} & \multirow[t]{2}{*}{485} \\
\hline Status & Unemployed & 72.96 & 8.70 & between & 278 & 87.521 & & \\
\hline Family & Nuclear & 71.14 & 9.75 & within & 1 & 2282.144 & 28.718 & 000 \\
\hline \multirow{2}{*}{ Income (Taka) } & $3,00-6,000$ & 71.57 & 9.52 & within & 1 & 3529.442 & \multirow[t]{2}{*}{47.072} & \multirow[t]{2}{*}{000} \\
\hline & $6,001-20,000$ & 79.48 & 5.88 & between & 278 & 74.979 & & \\
\hline
\end{tabular}

Gender $(\mathrm{f}=12.86, \mathrm{p}<.000)$, marital status $(\mathrm{f}=50.82, \mathrm{p}$ $=.000)$, education level $(\mathrm{f}=18.54, \mathrm{p}=.000)$, family type $(\mathrm{f}=$ $28.72, p=.000)$, and income $(f=47.07, p=.000)$ were found to be significant factors linked to older persons' quality of life scores. However, age ( $\mathrm{f}=2.41, \mathrm{p}=.122)$ and employment status ( $\mathrm{f}=.489, \mathrm{p}=.4850$ ) were found to be non-significant factors on older persons' quality of life scores.

\section{Discussion}

The present study found that most older persons reported a moderate overall quality of life score. They also reported moderate levels for all quality of life domains investigated. These results are higher than those reported in the study of older persons in a northern district of Bangladesh [12]. This variation could be due to differences between participants' ages, education levels and income levels. The present study's results are, however, consistent with the results of studies conducted in India [13] and Myanmar [14].

A higher mean quality of life score was found for males than for females. This result is consistent with the results of an Indian study [15], but inconsistent with the northern Bangladeshi study [12]. This inconsistency could be due to differences between two studies' older persons' characteristics. As regards marital status, married older persons reported a significantly higher mean quality of life score than divorced or widowed older persons. In addition, literate older persons showed a higher mean quality of life score than illiterate older persons. Also, older persons that lived in extended families reported a higher mean quality of life score than those that lived in nuclear families. These results are consistent with results of the studies in Bangladesh [12] and India [15].

Older persons with low family incomes reported a lower mean quality of life score than those with a middle or high family income. This finding is consistent with the results of studies in Bangladesh [12] and Brazil [16].

Age categories were a non-significant factor on quality of life scores, although younger groups reported higher mean quality of life scores than older age groups. This is consistent with other studies' results $[16,17]$. In the present study, older persons' employment status was also a non-significant factor on quality of life scores. This result is inconsistent with the results of the study in Bangladesh [12]. This may be explained by the fact that many older persons in the present study were engaged in non-income generating activities that may have contributed to their quality of life, such as household work, gardening, or looking after their grandchildren.

\section{Conclusion}

Older persons reported moderate overall quality of life scores. Gender, marital status, education level, family type, and income were the significant factors linked to elderly quality of life scores. These findings may be instructive for the development of plans for improving older persons' quality of life in rural areas of southern Bangladesh.

\section{List of Abbreviations}

ANOVA $=$ Analysis of variance.

WHOQOL $=$ World Health Organization Quality of Life.

$\mathrm{Tk}=$ Taka, the Bangladeshi currency $(80$ Taka $=1 \mathrm{USD})$.

$\mathrm{M}=$ Mean.

$\mathrm{SD}=$ Standard deviation

\section{Ethical Considerations}

Permission was obtained from a proper district level health authority. Written consent was taken from the study participants. Permission was obtained via email to use the Bengali version of the WHOQOL-BREF questionnaire.

\section{References}

[1] P. P. Datta, N. Gangopadhyay, and B. Sengupta, "Association of psychological morbidity with socio-demographic characteristics among elderly: A cross-sectional study from Eastern India," International Journal of Medicine and Public Health, vol. 3, no. 2, pp. 94-99, April 2013.

[2] Department of Economic and Social Affairs, World Population Ageing 2013. New York: United Nations, 2013.

[3] World Health Organization. Facts about ageing. September 2014.

[4] Directorate General of Health Services (Bangladesh), Health bulletin. Dhaka: Ministry of Health and Family Welfare, 2012.

[5] H. Kabir, H. T. A. Khan, M. Kabir, and M. T. Rahman, "Population ageing in Bangladesh and its implication on health care," European Scientific Journal, vol. 9, no. 33, pp. 34-47, November 2014. 
[6] Y. Khaje-Bishak, L. Payahoo, B. Pourghasem, and M. A. Jafarabadi, "Assessing the quality of life in elderly people and related factors in Tabriz, Iran," Journal of Caring Sciences, vol. 3, No 4, pp. 257-263, December 2014.

[7] D. V. Jeste et al., "Association between older age and more successful ageing: critical role of resilience and depression," American Journal of Psychiatry, vol. 170, no. 2, pp. 188-198, February 2013.

[8] M. N. Islam and D. C. Nath, "A future journey to the elderly support in Bangladesh," Journal of Anthropology, vol. 2012, pp. 1-6, 2012.

[9] World Health Organization Quality of Life Group, "Development of the World Health Organization WHOQOLBREF quality of life assessment," Psychological Medicine. vol. 28 , no. 3, pp. 551-558, May 1998.

[10] S. C. Mohapatra, I. S. Gambir, I. J. Singh, and N. K. Mishra, "Nutritional status in elderly people of Varanasi district," Indian Journal of Preventative and Social Medicine, vol. 40, no. 3, pp. 152-156, July 2009.

[11] Ministry of Health and Family Welfare (Bangladesh), Health bulletin. Dhaka: Directorate General of Health Services, 2016.

[12] M. N. Khan, M. N. I. Mondal, N. Hoque, M. S. Islam, and M. Shahiduzzaman, "A study on quality of life of elderly population in Bangladesh," American Journal of Health Research, vol. 2, no. 4, pp. 152-157, July 2014.

[13] S. Hameed, K. R. Brahmbhatt, D. C. Patil, K. S. Prasanna, and S. Jayaram, "Quality of life among the geriatric population in a rural area of Dakshina Kannada, Karnataka, India," Global Journal of Medicine and Public Health, vol. 3, no. 3, pp. 1-5, 2014.

[14] M. M. Naing, S. Nanthamongkolchai, and C. Munsawaengsub, "Quality of life of the elderly people in Einme Township Irrawaddy Division, Myanmar," Asia Journal of Public Health. vol. 1, no. 2, pp. 4-10. December 2010 .

[15] D. Kamra, "A community based epidemiological study on quality of life among rural elderly population of Punjab," International Journal of Recent Trends in Science and Technology, vol. 11, no. 2, pp. 192-197, June 2014.

[16] D. M. S. Tavares, L. L. Santos, F. A. Dias, P. C. S. Ferreira, and E. A. Oliveira, "Quality of life of rural elderly and associated factors," Journal of Nursing UFPE On Line, vol. 9, no. 11, pp. 9679-87, August 2015.

[17] H. A. Figueira, J. A. Figueira, D. Mello, and E. H. M. Dantas, "Quality of life throughout ageing," Acta Medica Lituanica, vol. 15, no. 3, pp. 169-172, 2008. 